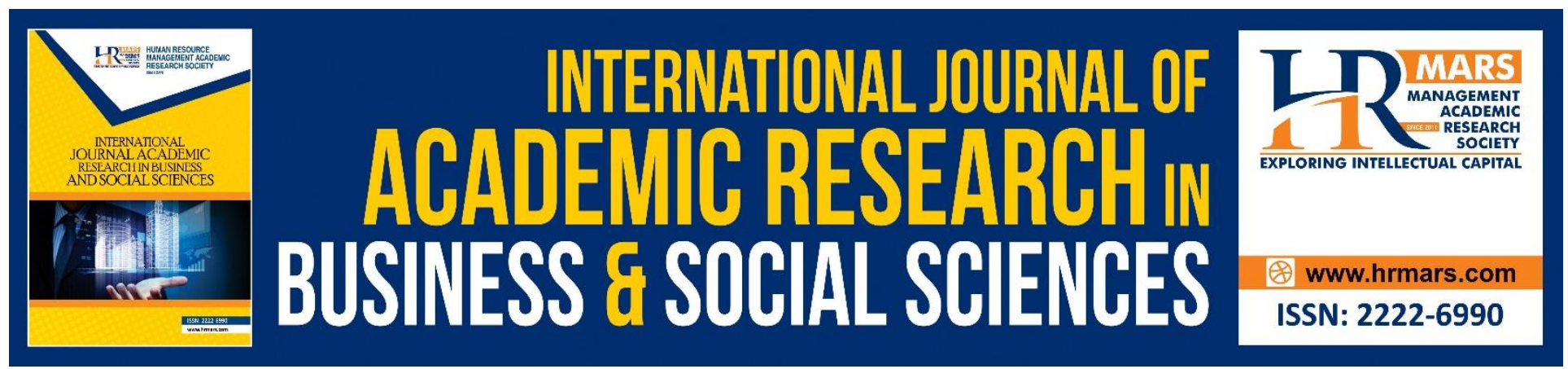

\title{
The Effect of Dark Tetrad Personalities Traits in Cyber Aggression Behavior among Johor Bahru Teachers
}

Nur Amirah Mohamed Yatim, Beni Widarman Yus Kelana, Zaiful Hasmi Mohd Hashim

To Link this Article: http://dx.doi.org/10.6007/IJARBSS/v10-i10/8021

DOI:10.6007/IJARBSS/v10-i10/8021

Received: 08 August 2020, Revised: 30 August 2020, Accepted: 19 September 2020

Published Online: 26 October 2020

In-Text Citation: (Yatim, Kelana, \& Hashim, 2020)

To Cite this Article: Yatim, N. A. M., Kelana, B. W. Y., \& Hashim, Z. H. M. (2020). The Effect of Dark Tetrad Personalities Traits in Cyber Aggression Behavior among Johor Bahru Teachers . International Journal of Academic Research in Business and Social Sciences. 10(10), 897-904.

Copyright: (C) 2020 The Author(s)

Published by Human Resource Management Academic Research Society (www.hrmars.com)

This article is published under the Creative Commons Attribution (CC BY 4.0) license. Anyone may reproduce, distribute, translate and create derivative works of this article (for both commercial and non-commercial purposes), subject to full attribution to the original publication and authors. The full terms of this license may be seen

at: http://creativecommons.org/licences/by/4.0/legalcode

Vol. 10, No. 10, 2020, Pg. 897 - 904

Full Terms \& Conditions of access and use can be found at http://hrmars.com/index.php/pages/detail/publication-ethics 


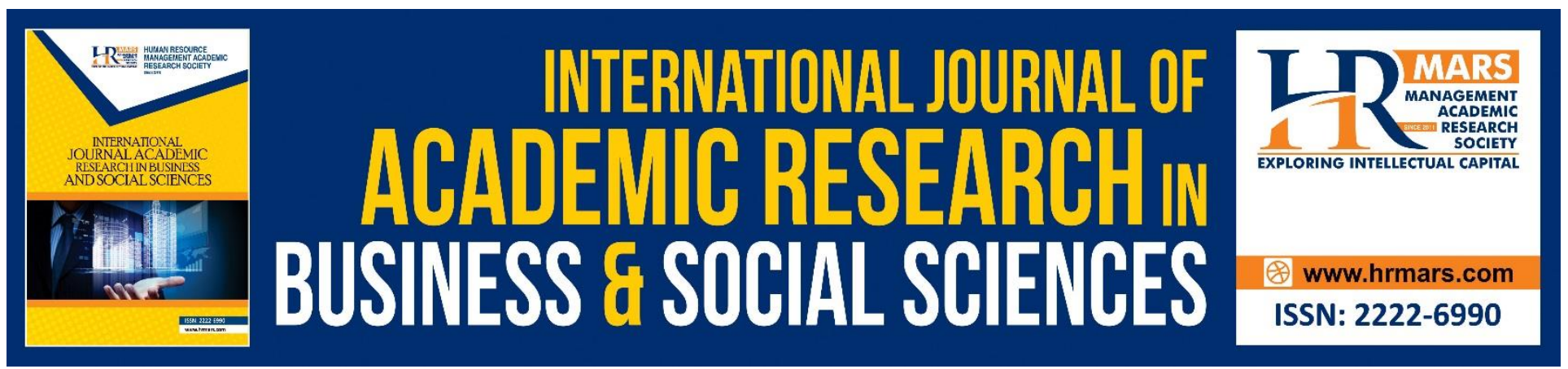

\title{
The Effect of Dark Tetrad Personalities Traits in Cyber Aggression Behavior among Johor Bahru Teachers
}

\author{
Nur Amirah Mohamed Yatim (a), Beni Widarman Yus Kelana(b) ${ }^{(\mathrm{b})}$ Zaiful \\ Hasmi Mohd Hashim(c) \\ ${ }^{1}$ (Azman Hashim International Business School, Universiti Teknologi Malaysia, 81100, Johor Bahru, \\ Malaysia) a , '(Azman Hashim International Business School, Universiti Teknologi Malaysia, 54100, \\ Kuala Lumpur, Malaysia) ${ }^{\mathrm{b}},{ }^{3}$ (Azman Hashim International Business School, Universiti Teknologi \\ Malaysia, 54100, Kuala Lumpur, Malaysia) ${ }^{\mathrm{c}}$

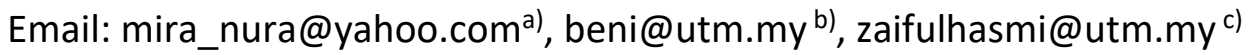

\begin{abstract}
This article was published, to identify and understand the roles of Dark Tetrad personality trait in cyber aggression behavior. Although social media offer much benefit and positivity, there is an increasing observable claiming that the social media possess a huge risk, for individual, communities, firm (either profit or non-profit organization), and eventually towards the society as a whole. According to the statistics by Malaysia Computer Emergency Response Team (MyCERT) (2020), the reported cases by the computer securities and cyber aggression related incidents in Malaysia has increase from 2016 to July 2020. There are some issues regarding on Malaysian teachers issuing negative statements in Facebook. Many study has been conducted in determining the Dark Triad personality association with the cyber aggression behavior. This study aims to examine the Dark Tetras personality traits that contributed to the cyber aggression behavior among teachers. This study has been conducted among 169 participants, which is the civil servant - teachers in Johor Bahru, Malaysia. The respondent has been chosen, as teachers represent the highest number of Malaysian civil servant. The study has been conducted quantitatively, and a sets of questionnaire, has been distributed via google doc to the respondents. The result shown that there has a significant relationship between the 4 construct in the Dark Tetrad personality with the cyber aggression behavior, whereby Psychopathy has become the highest element (based on the mean score) among the four Dark Tetrad personality traits. This study is expected to prove the Dark Tetrad personality conceptually; but the empirical evidence from the study can be used in order to facilitate more detailed future studies especially in dark personalities fields. It is also expected to improve understandings of the dark personalities of the teachers; as they are the role models in schools in order to increase the education quality in Malaysia, in tandem with the Malaysia Education Development Plan.
\end{abstract}


INTERNATIONAL JOURNAL OF ACADEMIC RESEARCH IN BUSINESS AND SOCIAL SCIENCES Vol. 10 , No. 10, 2020, E-ISSN: 2222-6990 @ 2020 HRMARS

Keywords: Social Media, Dark Triad Personality, Dark Tetrad Personality, Narcissism, Machiavellianism, Psychopathy, Sadism, Cyber Aggression and Teachers.

\section{Introduction}

The objective of the study is to identify the significant relationship between Dark Tetrad Personality traits and cyber aggression behavior. The study is the prolonged to the Dark Triad personalities model, into Dark Tetrad personalities model (with the addition of Sadism traits). The 4 construct, that is Narcissism, Machiavellianism, Psychopathy, Sadism and Cyber aggression has become the variables in this study. This study is conducted to fill the gap, which shows that less study has been conducted by using Dark Tetrad personalities traits in relation to the cyber aggression behavior, especially in the government sector. Cyber aggression behavior in social media usage has gone so far and have great negative impacts. Types of social media defiant behavior including uploading any negative comments as well on pictures, posting negative posts on other peoples wall, using pictures or videos in the intention of making fun of another user, stalking others, hacking others account or making posts as though another person wrote them [2].Thus, to overcome the issues of cyber aggression behavior in social media platform, the findings and discussion ns in this research is important to justify the significant relationship between the variables. According to [3] the negative usage of social media can be shaped by human personality, in which this factor has an important role to initiate, develop and maintain the addictive behaviors. The negative impact of cyber aggression behavior has gone beyond countries and is difficult to intervene. Recently, there were many issues arisen due to the defiant behavior of the social media to express dissatisfaction and hatred by the Malaysian, which had also involving public sectors and public servants, such as teachers. A wellfunctioning school is not only a school that promotes learning, but also attends to a healthy and socially appropriate behavior. This study is expected to prove the Dark Tetrad personality conceptually; but the empirical evidence from the study can be used in order to facilitate more detailed future studies especially in dark personalities fields. It is also expected to improve understandings of the dark personalities of the teachers; as they are the role models in schools in order to increase the education quality in Malaysia, in tandem with the Malaysia Education Development Plan.

\section{"LINKING PIN" BETWEEN DARK TETRAD PERSONALITY TRAITS AND CYBER AGGRESSION BEHAVIOR}

Table 1 presents a brief explanation of past studies showing the relationship between Dark Tetrad personality traits and cyber aggression behavior to strengthen the evidence conceptually: 
INTERNATIONAL JOURNAL OF ACADEMIC RESEARCH IN BUSINESS AND SOCIAL SCIENCES Vol. 10, No. 10, 2020, E-ISSN: 2222-6990 @ 2020 HRMARS

TABLE 1. Relationship between Dark Tetrad personality traits and cyber aggression behavior Dark Tetrad Personality Traits

In the study by [10], Narcissism can be described as the tendency to present oneself in a positive manner. They tried to be the centre of attention. The study shown that there was a relationship between Narcissism with observable Twitter behaviour. The study by [5] shown that Narcissism correlate positively with cyberbullying activities. Cyberbullying was one of cyber aggression behaviour, as the person will communicate using social media in attempting to harass, ostracize, impersonate or denigrate others. People with Narcissism always act and feel superior, entitled and grandiose. According to [12], high personality traits of Narcissism people gave a different picture from others trait. They tend to show off, and use Facebook more often and they tend to make dishonest post, and sometimes emotionally being cold. They predicted that there was no direct relation between Narcissism Machiavellianism Narcissism with surveillance in Facebook. People with this trait was very expert in manipulating their own profile. They do posting in Facebook for their self-aggrandizement and validation of themselves. The study conducted by [1] upon Russian Facebook users with the outstanding dark personalities traits has resulted that there were no direct relations between Narcissism and aggressive online behaviour. People with this trait like to wrote longer post, longer sentences and this reflect the consistency with the theory that they tend to exhibit themselves for attention attraction. In relative, some researcher proposed that teachers should have Narcissism traits [7]. This is because, the people of Narcissism fit into careers that involve in social and they are compatible to be leaders. Another proposed findings, Narcissist always fail to maintained good interpersonal relationships with their peers and subordinates [9],

According to the study by [10], Machiavellianism has the least relationship to the Tweeter behaviour, and they post less retweet. They show surface-level of charm (common with Narcissism) and lack of ethics (cynicism) which is similar to Psychopathy. Machiavellianism traits correlate positively with cyberbullying activities according to [5]. People with this trait tends to manipulate other people strategically The result in the study also reveal that Machiavellianism people has a positive correlation with visual and text based cyberbullying. [12] proposed that Machiavellianism and Facebook surveillance has a significant relationship. The result also shown that this trait has become the most dominant among others, and it has led to a greater Facebook surveillance. Specifically, those with high in this traits seem to have the tendency as they really like gossips, and often they will tell others about any news and information that they found, while looking at other people's profile. The study by [1] has resulted that Machiavellianism traits and aggressive online behaviour has no significant behaviour. People with this trait always put on less postings, with shorter sentences. Past researchers 


\begin{tabular}{|c|c|}
\hline & $\begin{array}{l}\text { predict that Machiavellianism was not suitable for caring occupations [7]. } \\
\text { People with this trait tend to challenge the status quo, and may be less } \\
\text { satisfied with the career. }\end{array}$ \\
\hline Psychopathy & $\begin{array}{l}\text { [10] proposed that Psychopathy show a very distinctive pattern from } \\
\text { Narcissism and Machiavellianism. This trait has the highest correlation with } \\
\text { the Tweeter behaviour. Psychopathy people will talk about violence in an } \\
\text { angry manner. A study by [4] found that Psychopathy was correlated } \\
\text { positively with cyberbullying. They found that Psychopathy has lack of } \\
\text { empathy and always been the impulsive and thriller seeker behaviour. } \\
\text { Psychopathy has become the most dominant of the others trait, and this has } \\
\text { been proved by previous study, that Psychopathy tends to be the most } \\
\text { problematic than others. Study by [12] Psychopathy has a relationship with } \\
\text { the Facebook surveillance. The people with this trait tends to dislike the } \\
\text { uncertainty feelings, and often tried to reduce this feeling. There is also } \\
\text { suggestion that people that was high in this traits tends to feel pleasure for } \\
\text { spying on other people life, with the character of less empathy and high } \\
\text { callous. The study conducted by [1] has resulted that there was a significant } \\
\text { relationship between Psychopathy traits with aggressive online behaviour. } \\
\text { This trait has become the most unique and prominent traits among others. } \\
\text { They have the tendency to being attracted on political discussions and, one } \\
\text { of the interpretation was that they revolve around power issues much, and } \\
\text { they found that authority and conflict issues was very attractive. [7] also } \\
\text { suggest that Psychopathy people tends to create disruptive tactics in order } \\
\text { to get their plan work out }\end{array}$ \\
\hline Sadism & $\begin{array}{l}\text { Sadism was the latest trait that has been expanded, in as Dark Tetrad. This } \\
\text { trait was closely related to the tendency to feel pleasure in others suffer, and } \\
\text { it was also found out that this trait was a distinct construct from the Dark } \\
\text { Triad [13]. The result of the study shown that, Sadism has become the most } \\
\text { significant predictors, as compared to other traits This was in contra with the } \\
\text { study result of [5] that found out Psychopathy as the most prominent trait. } \\
\text { But the model been used by [5] was only Dark Triad, without Sadism. Thus, } \\
\text { this study concluded that this trait was more predictive for online antisocial } \\
\text { behaviour, much than Dark Triad; and has been driven by the sadistic } \\
\text { pleasure, strategic considerations as well as threatened ego. A study on } \\
\text { problematic social media usage has shown that Sadism has a direct } \\
\text { association with cyberbullying, cyberstalking and cyber trolling [8] This trait } \\
\text { has become the most dominant trait, when it's been added in the Dark Triad } \\
\text { model. In a study upon Malaysian university student, it shown that Sadism } \\
\text { has no significant relation with the social media addiction impulsivity [3] The } \\
\text { study resulted as Psychopathy has a positive correlation with the social media } \\
\text { addiction activities. This was supported by the previous study that, } \\
\text { Psychopathic people usually being motivated to use social media in an } \\
\text { extensive manner, in order to express their dark trait. }\end{array}$ \\
\hline
\end{tabular}


INTERNATIONAL JOURNAL OF ACADEMIC RESEARCH IN BUSINESS AND SOCIAL SCIENCES Vol. 10, No. 10, 2020, E-ISSN: 2222-6990 @ 2020 HRMARS

\section{Method}

According to [6] SEM is one of the family in statistics model, that is important in determining and explaining the relationship between multiple variables. According to [11] SEM has become a popular and important tools in statistics, for the researcher to seek for the relationships that has been proposed in a parsimonious model. SEM is a better statistical technique, as compared to the other multivariate techniques, including path analysis, factor analysis as well as multiple regression. The data will be collected quantitatively. Quantitative data consists of data in the form of numbers and statistics, and will be gathered by using questionnaires to provide statistical data. This study will be conducted by distributing the questionnaire via social media platform, as it is going to use the Triad Theory testing, that require the researcher to put a distance away from this research; so as not to bias the results.Cluster random sampling technique was used in the study involving a sample of 178 people. Whereas, the sample was left with just as many as 169 people after the validity and reliability process was carried out. The unit of analysis is the study of the teachers, which is from government sector in Malaysia.

\section{Result and Discussion}

This research analysis has been carried out based on the data collected, in order to achieve the objectives of this research. Descriptive analysis has been done by using SPSS $v$ 23, that providing analysis upon the respondent demographic data. Besides, the first objective, in which to find the independent variables with the highest level has been determined by using score min value. The result shown that Psychopathy is the highest level of personality traits among the respondent; whereby the lowest is Narcissism personality traits. Next, the second objective is to seek for the significant relationships (value $\mathrm{P} \leq 0.05$ ) between Dark Tetrad personality traits and the cyber aggression behavior upon school teachers. The result shown that for the 4 construct of independent variable (Narcissism, Machiavellianism, Psychopathy and Sadism), there is significant relationship between the independent variable and the dependent variable (cyber aggression behavior). Thus, hypothesis $\mathrm{H} 1 \mathrm{a}, \mathrm{H} 1 \mathrm{~b}, \mathrm{H} 1 \mathrm{c}$ and $\mathrm{H} 1 \mathrm{~d}$ is accepted. The summary of the research objective findings can be seen in Figure 1 below. This shows that the Dark Tetrad personality traits contibute to a crucial impact on cyber aggression behavior, as being develop by Paulhus.

This study has been exploring the cyber aggression behavior in relation to the Dark Tetrad personality when using the social media. The four traits of Dark Tetrad personalities have significant relationships and effects cyber aggression behavior among civil servants, especially teachers who was the respondents in this study. The study also found that Psychopathy is the most dominant trait among others, and the screening upon civil servants who have these traits at a high rate can be made, to facilitate monitoring the cyber aggression activities in the future. Since teachers are a noble job, and they set a good example for their students, ownership of these behaviors needs to be controlled, and social media usage should always adhere to the established guidelines. An effective prevention plan may be made by the government of Malaysia, to ensure a healthy and safe environment among civil servants, while browsing social media 


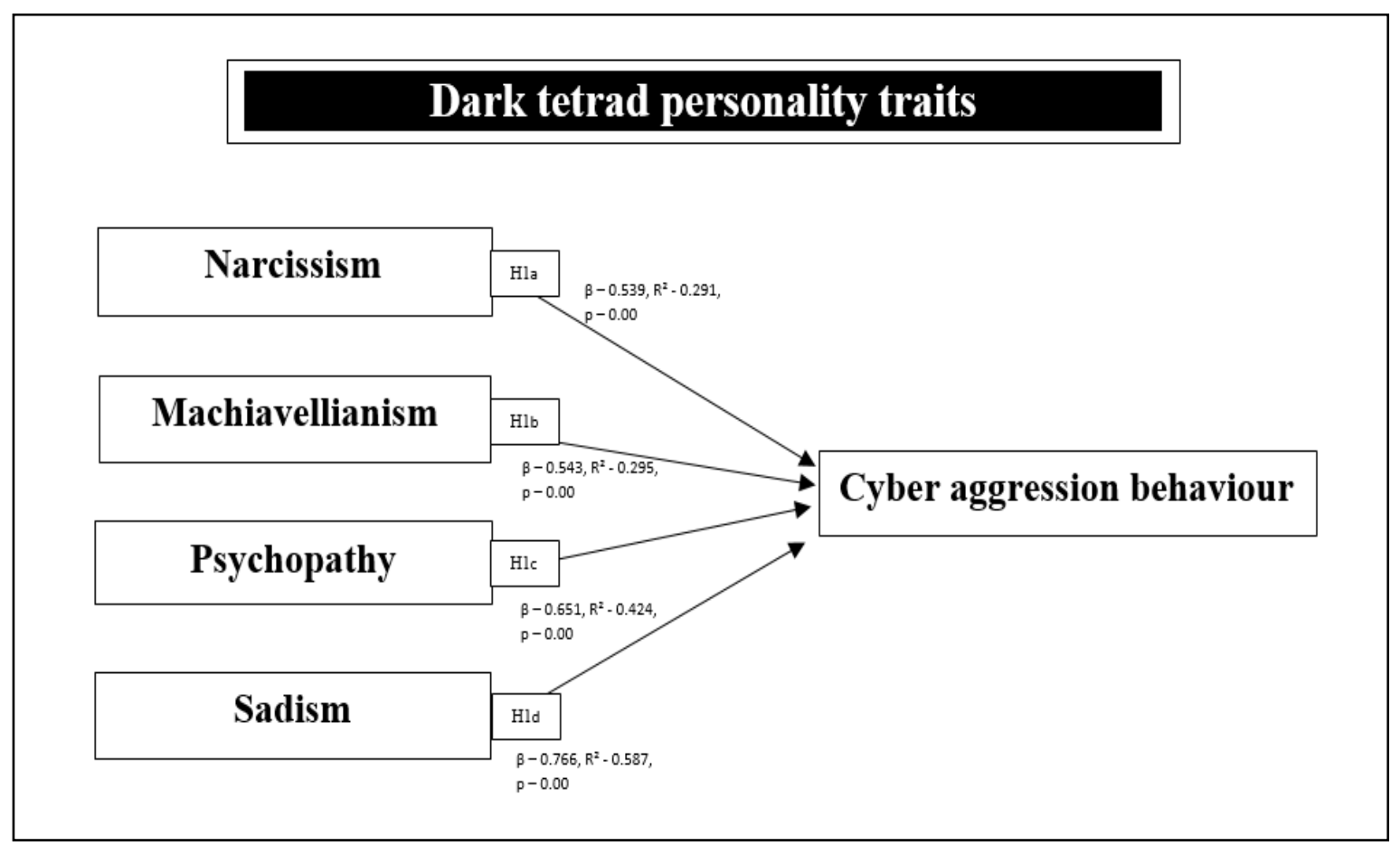

FIGURE 1. Result of SEM analysis (Significant effects of Dark Tetrad personality traits and cyber

\section{Conclusion} aggression behavior)

In conclusion, this study has found the evidence in conceptual and empirical, to justify on how Dark Tetrad personality traits may enhance the understanding of the human personality traits. It is also expected to contribute in improving the understandings of the dark personalities of the teachers; as they are the role models in schools in order to increase the education quality in Malaysia, in tandem with the Malaysia Education Development Plan. At the end of this study, there are several opportunities for future reseacrcher to carry further study upon this issues, including examine new factors that could contribute to the level of dark personality traits in greater depth.

\section{Contribution}

Theoretically, this study has contributed, in measuring of dark personalities by using the Dark Tetrad theory, whereby previous researchers have often used the Dark Triad theory. This study had extended and using the latest trait, Sadism to be include in the Dark Triad. Basically, studies on Dark Tetrad personalities are also still lacking, as compared to Dark Triad. The results of this study can be acting as a trigger to Malaysia public service sector (in general) and the Ministry of Education (in particular) to implement personality tests on all the employees; so that the true character of employees can be understood. Once the test is conducted, an action plan can be formed based on the feedback given by the employee. The action plan refers more to the suitability of the personality to the position held and the field of work held at the time. This also may be use upon the intake on new staff, and may help to filter the suitable candidates. 
INTERNATIONAL JOURNAL OF ACADEMIC RESEARCH IN BUSINESS AND SOCIAL SCIENCES Vol. 10, No. 10, 2020, E-ISSN: 2222-6990 @ 2020 HRMARS

\section{Acknowledgments}

This work has been supported by Universiti Teknologi Malaysia. Gratitude would like to be expressed to Dr Beni Widarman Yus Kelana, for the continuous guidance and assistance in the process submission of this research article. Gratitude also goes to Jabatan Perkhidmatan Awam Malaysia (JPA) for the grant of scholarship for me to pursue study in Master in Business Administration.

\section{References}

Bogolyubova, O., Panicheva, P., Tikhonov, R., Ivanov, V., \& Ledovaya, Y. (2018). Dark personalities on Facebook: Harmful online behaviors and language. Computers in Human Behavior, 78, 151159. https://doi.org/10.1016/j.chb.2017.09.032

Choo, M. S., Yiyuan Xu, Maynard, A., Hayashi, K., \& Nakamura, B. (2016). Running Head: Cyberbullying In Malaysian Adolescents.

Chung, K. L., Morshidi, I., Yoong, L. C., \& Thian, K. N. (2019). Personality and Individual Di ff erences The role of the dark tetrad and impulsivity in social media addiction : Findings from Malaysia, 143(October 2018), 62-67.

Furnham, A., Richards, S. C., \& Paulhus, D. L. (2013). The Dark Triad of Personality : A 10 Year Review, 3, 199-216.

Goodboy, A. K., \& Martin, M. M. (2015). The personality profile of a cyberbully: Examining the Dark Triad. Computers in Human Behavior. https://doi.org/10.1016/j.chb.2015.02.052

Hair, Jr, J. F. (2015). Essentials of Business Research Methods. Essentials of Business Research Methods. https://doi.org/10.4324/9781315704562

Kay, C. S., \& Saucier, G. (2020). Insert a joke about lawyers: Evaluating preferences for the Dark Triad traits in six occupations. Personality and Individual Differences, 159(August 2019), 109863. https://doi.org/10.1016/j.paid.2020.109863

Kircaburun, K., Jonason, P. K., \& Griffiths, M. D. (2018). The Dark Tetrad traits and problematic social media use: The mediating role of cyberbullying and cyberstalking. Personality and Individual Differences, 135(June), 264-269. https://doi.org/10.1016/j.paid.2018.07.034

Nuzulia, S., \& Why, F. Y. P. (2020). When the Dark Shines: The Role of Dark Personality Traits in Leadership Role Occupancy and Hiring Decisions in a Collectivistic Culture. Social Psychological and Personality Science. https://doi.org/10.1177/1948550619893956

Preotiuc-Pietro, D., Carpenter, J., Giorgi, S., \& Ungar, L. (2016). Studying the Dark Triad of Personality through Twitter Behavior, 761-770. https://doi.org/10.1145/2983323.2983822

Sekaran, U., \& Bougie, R. (2003). Research method for business: A skill building approach, 5th edition. United States: John Wiley \& Sons Inc.

Stiff, C. (2018). The Dark Triad and Facebook Surveillance: How Machiavellianism, Psychopathy, But Not Narcissism Predict Using Facebook To Spy On Others, Computers in Human Behavior. https://doi.org/10.1016/j.chb.2018.12.044

Van Geel, M., Goemans, A., Toprak, F., \& Vedder, P. (2017). Which personality traits are related to traditional bullying and cyberbullying? A study with the Big Five, Dark Triad and sadism. Personality and Individual Differences. https://doi.org/10.1016/j.paid.2016.10.063 